\title{
Erratum to: Contrasting effects of blue and red LED irradiations on the growth of Sargassum horneri during the germling and immature stages
}

Osamu Miki ${ }^{1}$ Chikako Okumura $^{1}$ - Mawardi Marzuki ${ }^{1}$ Yusuke Tujimura ${ }^{1}$.

Takahito Fujii $^{1}$ - Chika Kosugi ${ }^{2}$. Toshiaki Kato ${ }^{2}$

Published online: 4 February 2017

(C) Springer Science+Business Media Dordrecht 2017

Erratum to: J Appl Phycol(2016)

DOI 10.1007/s10811-016-1026-x

The original version of this article unfortunately contained a mistake. Figure 7 was incorrect. The correct Figure is given below:

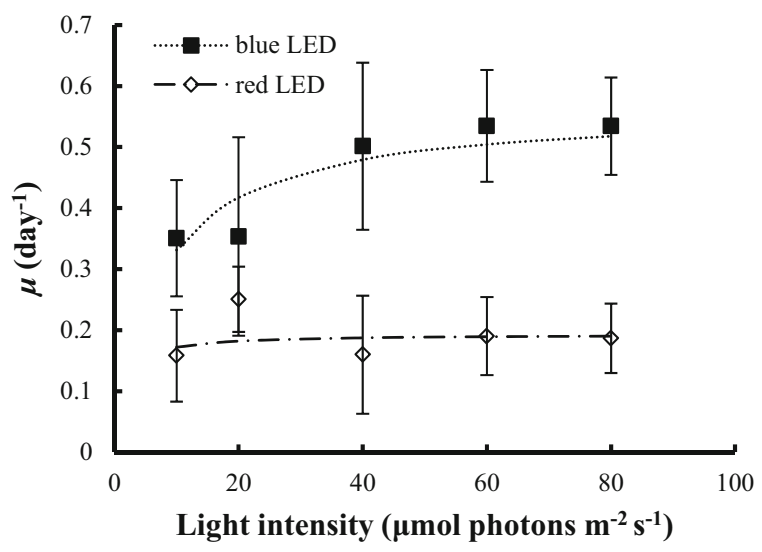

The online version of the original article can be found at http://dx.doi.org/ 10.1007/s10811-016-1026-x.

Osamu Miki

mikiosamu@se.kanazawa-u.ac.jp

Institute of Science and Engineering, Kanazawa University,

Kakuma-machi, Kanazawa, Ishikawa Prefecture 920-1192, Japan

2 R \& D Laboratories, Nippon Steel and Sumitomo Metal Corporation, 20-1, Shintomi, Futtsu, Chiba Prefecture 293-8511, Japan 